\title{
Avaliando a compreensibilidade de pictogramas em sistemas de wayfinding design
}

\author{
Evaluating the comprehensibility of pictograms on wayfinding design systems
}

Renato C. Mesquita

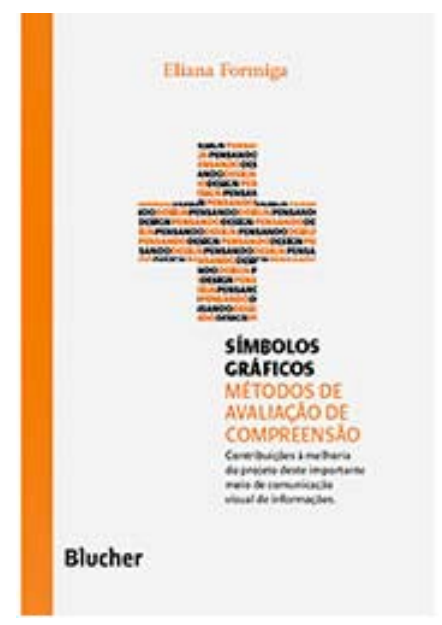

FORMIGA, Eliane. Símbolos gráficos: Métodos de avaliação e compreensão. Coleção Pensando o Design, Marcos Braga (coordenador). São Paulo: Editora Blucher. 2012. 148 p. ISBN: 9788521206460

\section{Resumo da obra}

O livro é uma revisão crítica da dissertação de mestrado defendida pela professora Eliana Formiga em 2002. A proposta é avaliar a eficiência (compreensibilidade) dos símbolos gráficos e pictogramas utilizados nos sistemas de wayfinding design dos hospitais públicos da cidade do Rio de Janeiro. Aplicando métodos científicos de ergonomia informacional a autora atinge o seu objetivo e deixa clara a importância desse tipo de avaliação de usabilidade, tanto na fase de projeto (pré-testes) como pós implantação, com a preocupação de tornar os símbolos mais compreensíveis e inclusivos.

\section{Summary of the book}

The book is a critical review of the lecturer Eliana Formiga's master dissertation in 2002. Her proposal is to evaluate the effectiveness (comprehensibility) of graphic symbols and pictograms used in the design of wayfinding systems for public hospitals in the city of Rio de Janeiro. Employing scientific methods of information ergonomics, the author reaches her aims and makes clear the importance of this kind of usability evaluation in both the project initial phase (pré-tests) and post-implementation, always with the concern of making the symbols comprehensible and inclusive.

De acordo com Green (1979, apud MENEZES \& PASCHOARELLI, 2009, p. 213), os símbolos gráficos são imagens utilizadas para representar um objeto, uma função ou um sistema. São instrumentos de comunicação não verbal. Essas formas de comunicação baseiam-se em mensagens decodificáveis pela capacidade sensorial. Fica claro, então, que se o público não compreende a mensagem, ela perde sua função. Perde o sentido. Perde o significado. E se não 
soubermos medir em que medida a mensagem é compreendida, não temos como saber se o projeto está no caminho certo ou não.

No capítulo 1, página 19, a autora afirma que "O design carece de mais pesquisas...". Essa afirmação é verdadeira para qualquer campo de atuação do designer. É preciso criar o hábito de submeter os projetos à avaliação do público-alvo para obter feedback - e naturalmente ter a humildade de alterar projetos para adequá-los à cultura e repertório daqueles a quem o projeto se destina. Aliás, embora pareça elementar, os designers que responderam o questionário proposto pela autora afirmam que "... quanto à checagem de compreensibilidade, ela é feita pelos designers do próprio escritório." Ou seja, os resultados obtidos são válidos para um perfil de público que não é - necessariamente - o mesmo que irá se utilizar do sistema, criando um conflito e em alguns casos até invalidando o teste.

O grande mérito da obra é aplicar métodos científicos para testar o grau de compreensão dos símbolos gráficos e pictogramas. Assim, a decisão é tomada com base científica, o que tira o design da dimensão meramente estética.

Os três capítulos iniciais (cerca de $25 \%$ do volume) introduzem o leitor aos principais conceitos do design de informação, comunicação por meio de signos, semiótica e ergonomia informacional. Bem embasados e citando autores como Frutiger (1997), Brugger (1996), Ota (1987), Pierce (1996) e Walther-Bense (2000) além das normas ISSO e AIGA, estes capítulos cumprem o papel de alinhar premissas conceituais, embora tenham pouca relevância para a aplicação da pesquisa em si ou para os resultados.

A partir daí a autora detalha métodos, técnicas e testes de eficiência comprovada e reconhecidos internacionalmente para medir a compreensibilidade de símbolos tanto para wayfinding design como para outros fins, como avisos e advertências em embalagens e equipamentos. Os métodos apresentados são:

1. Métodos de pré-seleção

2. Método de produção

3. Teste de compreensão

4. Método de reidentificação

5. Teste de eleição

6. Teste de classe de adequação

7. Teste de distribuição de classes de adequação

8. Teste de estimativa de compreensibilidade

9. Teste de correspondência

10. Métodos de pós-ocupação

11. Teste de procedimento da ISSO 9186

12. Processo de avaliação de símbolos do AIGA (três dimensões de avaliação: sintática, semântica e pragmática)

De maneira geral os métodos e técnicas são apresentados de forma clara e concisa, o que facilita muito a compreensão da pesquisa detalhada a seguir, que consistiu da aplicação de quatro testes aos símbolos gráficos usados na sinalização dos hospitais e serviços de saúde pública do Rio de Janeiro em 2002 para identificar sete referentes: sala de espera, emergência, enfermaria, farmácia, ambulatório, admissões e informações.

A seleção dos símbolos e pictogramas a serem avaliados foi feita a partir de:

- um questionário enviado para designers com reconhecida atuação em projetos de sinalização e wayfinding onde se perguntava as fontes mais usadas para o design de pictogramas e também se a compreensibilidade dos símbolos era testada. Como a prática mostra, a maioria dos designers testa os símbolos com sua equipe de trabalho ou com o círculo de pessoas mais próximas, sem se preocupar em ter uma amostra com perfil semelhante ao do público usuário do sistema.

- levantamento de símbolos em hospitais públicos e privados 
- levantamento de símbolos em referências bibliográficas de relevância nesse nicho de atuação

A amostra inicial de símbolos e pictogramas foi submetida a análise de três designers com destacada atuação no segmento e a pré-testes de compreensibilidade, dos quais resultaram 49 símbolos (sete para cada referente) que foram levados à pesquisa, onde foram aplicados os testes de produção, compreensão, reidentificação e estimativa de compreensibilidade.

No teste de produção, pede-se que os próprios usuários desenhem o que lhes vem à cabeça para identificar cada conceito. Independente da habilidade de representação gráfica, esse teste permite identificar elementos comuns ao repertório dos usuários e traz subsídios importantes para o design de símbolos gráficos. Os resultados do teste estão ilustrados no livro, possibilitando a comparação entre os desenhos e a análise dos elementos gráficos mais usados para cada referente.

O teste de compreensão tem o objetivo de avaliar cada símbolo separadamente a partir da resposta para a pergunta: "Que local do hospital este desenho indica?" (a pergunta original, "O que este desenho significa?" foi mudada porque algumas respostas eram uma interpretação da sintaxe do desenho, e não de seu significado). A pesquisa considera o grau de $66 \%$ de média como aceitável nos testes de compreensão (conforme normas ISO 9186-2001). Os resultados do teste são apresentados de forma clara em gráficos de linha, permitindo a comparação dos resultados para cada símbolo.

O teste de reidentificação parte da premissa de que alguns símbolos possam não ser claros à primeira vista, mas uma vez entendido ele passa a fazer parte do repertório do receptor. Resumidamente, o teste consiste em apresentar aos usuários todos os símbolos com uma legenda abaixo (durante 3 segundos cada) e depois apresentar os mesmos símbolos sem a legenda, para medir quais foram "aprendidas" e quais não foram. Esse teste é distante da situação real e por isso sua relevância pode ser questionada, mas a autora é coerente ao justificar sua aplicação principalmente para certificar as respostas do teste de compreensão, apurando o potencial do símbolo vir a ser memorizado depois de ser aprendido.

Finalmente o teste de estimativa que estima um grau (de 0 a $100 \%$ ) de compreensibilidade correspondente ao percentual de indivíduos que irá compreender corretamente o significado de cada símbolo. Embora obtido a partir da opinião dos participantes, este teste é aceito também por outros autores (Tromellen, Zwaga, 1998 apud MEDEIROS, VILLELA \& PEREIRA, 2011) e recomendado pela ISO 9186-2001 como único para aceitação de um símbolo de informação pública desde que seja alcançado o índice de $87 \%$. Devido ao nível de escolaridade dos usuários ser bastante diverso, a autora teve o bom senso de transformar os percentuais em uma escala de valores para facilitar a aplicação do teste.

Embora direcionado a um programa específico (hospitais), fica claro que esse tipo de avaliação da compreensibilidade dos símbolos gráficos pode ser aplicado a qualquer ambiente, e se bem interpretado contribuir para tornar as mensagens mais claras e facilitar a orientação dos fluxos de pessoas e veículos.

Além disso, estabelece um referencial teórico importante para os designers que, por dêsconhecimento dos métodos, avaliam os símbolos gráficos de forma informal com pessoas do próprio escritório ou de casa obtendo resultados inconclusivos dada a diferença do modelo mental do projetista e do usuário.

O aspecto negativo é a revisão geral do texto. Erros de digitação do nome de autores citados podem colocar em dúvida a fonte (Pierce é citado como "Peirce" diversas vezes no capítulo 1. "Carr" é citado como Car). Também falta atenção na formatação de partes do texto, principalmente título e corpo de tabelas que foram diagramados como texto corrido, dificultando a leitura (ver págs, 107 e 142). Além disso, quebra de página entre o título e o corpo da tabela, quebra de linha errada (pág 47,59), falhas de digitação e concordância (pág. 42,62) e até o caso de parte de um parágrafo que foi cortada (pág. 61). design.

De qualquer forma, uma boa leitura para projetistas, pesquisadores e estudantes de wayfinding 


\section{Referências}

MEDEIROS, Cindy Renate Piassetta Xavier, VILLELA, Cristiane da Silva Santos, PEREIRA, Vera Lúcia Duarte do Vale - Desenvolvimento de símbolos de advertências compreensíveis, Revista Ação Ergonômica, volume 5, número 1, 2010

MENEZES, Marizilda dos Santos e PACHOARELLI, Luis Carolso (org.) - Design e planejamento: aspectos tecnológicos - São Paulo : Cultura Acadêmica, 2009.

\section{Sobre o autor}

Renato Carneiro Mesquita, arquiteto e designer (FAUUSP, 1993), pós-graduado em Marketing (FGV-CEAG, 2006) e mestrando em Arquitetura e Design (FAUUSP). Professor do Centro Universitário Belas Artes de São Paulo de 2005 a 2011, coordenador do Master em Design Estratégico do Instituto Europeu de Design (2010), professor convidado dos cursos de design da ESPM, FAUUSP e Universidade Anhembi Morumbi desde 2009, do MBA do IPOG (Goiânia) desde 2009 e do MBC da Universidade de São Caetano do Sul desde 2009. 